\title{
A Quasi-Experimental Study to Assess Consequences of Early Versus Delay Umbilical Cord Clamping on Maternal and Neonatal Outcomes in Beni-Suef city
}

\author{
Safaa Soliman Ahmed ${ }^{1}$, Sahar Sedky Faheim², Hanan Elzeblawy Hassan ${ }^{1 *}$ \\ Mohamed Meabed ${ }^{3}$ \\ ${ }^{1}$ Maternal \& Newborn Health Nursing, Faculty of Nursing, Beni-Suef University, Egypt \\ ${ }^{2}$ Pediatric Nursing, Faculty of Nursing, Beni-Suef University, Egypt \\ ${ }^{3}$ Professor of pediatrics, Faculty of Medicine, Beni-Suef University, Egypt \\ ${ }^{1 *}$ Hanan Elzeblawy Hassan, Faculty of Nursing, Beni-Suef University, Egypt \\ nona_nano_1712@yahoo.com
}

Abstract

Background: Timing of an umbilical cord clamping is considering as achallenging undertaking for improving maternal \& neonatal quality outcomes.

Aim: To compare the effects of early versus late umbilical cord clamping on maternal \& neonatal outcomes in Beni-Suefcity.

Design: A quasi-experimental study conducted with a purposive of 150 predominantly Upper Egyptian laboring women were eligible collected from labor ward in Beni-Suef General hospital.

Tools: A Structured Interviewing Questionnaire Sheet and Maternal \& Fetal Outcome Sheet were used.

Results: No significant difference between DCC \& ECC groups in relation to estimated maternal postpartum blood loss, maternal hemoglobin, hematocrit levels and needs for blood transfusion,moreover, the effects of late cord clamping on neonate reported that rise in hematocrit \&hemoglobin level at birth, especially among late cord clamping group. The late cord clamping was negatively correlated with treatment with phototherapy, admission to the NICU, respiratory distress, jaundice requiring phototherapy, with need for resuscitation, polycythemia and prevent incidence of anemia.

Conclusion:Deferred times for umbilical cord clamping didn't increase the risk of maternal post-partum hemorrhage, duration of the $3^{\text {rd }}$ stage of labor or the need for manual removal of the placenta, however, it significantly increased neonatal hemoglobin, hematocrit, and bilirubin, polycythaemia, and transient tachypnoea in the newborn.

Recommendations: Institutionalization of DCC in all governmental hospitals \&medical educational settings and do not extend time of DCC to decrease risk of DCC such as (hyperbilirubinaemia, polycythaemia, \& transient tachypnea).

Keywords: Early, delay, umbilical cord clamping, maternal' outcomes, neonatal outcomes.

\section{INTRODUCTION}

Nowadays, the timing of umbilical cord is considering a growing area of research. The researchers looking for optimize maternal \& neonate outcomes. The early umbilical camping is determined as the umbilical cord being clamped around one minute after birth, while late clamping usually reserved for more than one minute minutes, however studies reported that in most deliveries, clamping the cord is performed immediately after 
birth within 10 to15 seconds with baby maintained at or below the level of the placenta. ${ }^{[1,2]}$ World health organization (WHO) recommended that delay cord clamping in the low \& middle-income countries may be beneficial. ${ }^{[3,4]}$ The reduction of neonatal risk for administration blood transfusion and consequences such fluid overload, necrotizing enterocolitis \& blood-borne pathogens can be achieved by implementation of delayed cord clamping. ${ }^{[5]}$

In early cord clamping (ECC) the cord is usually clamped just following the birth of the infant; this is mostly carried out in the first 30 seconds after birth; nevertheless of whether the cord pulsation has ended. ${ }^{[6]}$ Delayed or late cord clamping (DCC) isa physiological method, involves clamping the cord after one minute or more (1-3 minutes), after birth or when cord pulsation has stopped. However, meanings of what establishes early and late cord clamping vary if the umbilical cord isn'tclamped. The umbilical circulation usually stops when the umbilical arteries close, so the cord will stop its pulsating. ${ }^{[7]}$ There are studies displayedaltered points in the time of cord clamping worldwide and there is slight agreement among doctors and midwives about the best time to clamp the cord after birth. Maternal \& infant safety is considered the most important point of difference. Worldwide, a lot healthcare providersare likely to clamp the umbilical cord after deliveryof the baby as quickly as possible. ${ }^{[8,9]}$

The WHO had combined this intervention as active management of the $3^{\text {rd }}$ stage of labor (AMTSL). ${ }^{[1]}$ Later on, numerous researches had been done to evaluate the effectiveness of each component of AMTSL. ${ }^{10,11]}$ The administration of uterotonic drugs had been recognized as the most vital element of the intervention, while the profits of ECCand controlled cord traction is still contentious. ${ }^{[12]}$ The WHOhad shown many trials and demonstrated that ECCdidn't increase any welfare to the prevention of post-partum hemorrhage (PPH). It may disturb the duration of the $3^{\text {rd }}$ stage of labor, which isasignificant issue for busy staff in the delivery room. ${ }^{[1]}$ Consequently, the WHOchanged the AMTSLto contain: first, administration of uterotonic drugs immediately after delivery of the fetus; the favored uterotonic drug is oxytocin. Second, delayed cord clamping (DCC) for at least 1-3 minutes to decrease infant anemia and organized cord traction conducted only if required. ${ }^{[12]}$

The quality improvement initiative for DCCin alow-birth-weight (LBW) infants and the recommendation reported by Bolstridge et al (2016) ${ }^{[13]}$, that DCCis usedfor the newborn before thirty-seven weeks gestational age, it improves overall clinical neonatal outcomes. ${ }^{[14]}$ Furthermore, the transference period from fetal to newborn life is considering one of the major physiological challenges in all human may face, however, once the umbilical cord is clamped, infants must clear their airway for allowing gas exchange,as well as the cardiovascular system, must undergo amajor structural and organ functional rearrangement. ${ }^{[15-17]}$

In fact, the timing of cord clamping and following strategies and policies carried out for active management in the $3^{\text {rd }}$ stage of labor to reduce postpartum hemorrhage, consequently, considered the DCCmay increase the risk of maternal hemorrhage. Conversely, inareview of five trials that consisted more than 2200 women, late umbilical cord clamping was not associated with an increased risk of PPH or increased blood loss at deliveryand reported nor was arelationship with a difference in PPH level or need for blood transfusion. ${ }^{[18]}$

\section{SigNIFICANT OF THE STUDY}

The timing of acord clamping has agrowing area of research and reporting many clinical benefits. However, the implementation of new evidence is considering as achallenging undertaking for improves neonates' quality outcomes. ${ }^{[14]}$ As the nursing care is the main critical component in labor unit, Nurses' poor manipulation of the third stage of labor surely will interfere with their ability to achieve positive pregnancy outcomes. ${ }^{[19]}$ Recent studies have now begun to investigate the factors associated with the timing of umbilical cord clamping and how it can improve infant and maternal outcomes. ${ }^{[20]}$ So the current study aimed tocompare the effectiveness of ECCversus DCCon the maternal \&newborn outcome. While WHO,as well as the International Federation of Obstetrics \& Gynecology no longer support the ECCas apart of the Active management of the $3^{\text {rd }}$ stage of labor 
A Quasi-Experimental Study to Assess Consequences of Early Versus Delay Umbilical Cord Clamping on Maternal and Neonatal Outcomes in Beni-Suef city

(AMTSL). Furthermore, DCC may play avital role in the decline of anemia during infancy. In Egypt, according to the results of arecent study conducted by Elgzaret al (2017) ${ }^{[21]}, 57.1 \%$ of infants in Menoufiagovernorate, Egypt have iron deficiency anemia, but DCC may well increase rates of hyperbilirubinaemia, polycythaemia, and transient tachypnea in the newborn. ${ }^{[22]}$ Complications of polycythemia in the newborn are bleeding, thrombotic, \& vascular complications are the major causes of morbidity and mortality. ${ }^{[23]}$

\section{AIM OF THE STUDY}

The present study was conducted to evaluate the consequences of ECC versus DCC on maternal \& neonatal outcomes in Beni-Suef city.

\section{HYPOTHESES OF THE STUDY}

The DCC will have clinical benefits on both maternal \& neonatal outcome than ECC.

\section{SubJeCtS ANd Methods}

Research Design: A quasi-experimental research design was selected for the current study.

Research Setting: The study was conducted at labor \& delivery units at Beni-Suef General hospital.

Sample Size and Technique: The sample size was detected based on the last year census report of the obstetrics and gynecology department at Beni-Suef General Hospital. The total number of multipara pregnant women was $1490 .{ }^{[24]}$ The sample size was calculated by taking $10 \%$ of the total annual rate.Randomized controlled trialused for comparing DCC with ECC. The sample size was detected based on the last numbers of previous setting students was 298 . The sample size was calculated utilizing the following formula. ${ }^{[25]}$

$$
n=\frac{N}{1+N(\varepsilon)^{2}}
$$

Where $\mathrm{n}=$ sample size, $\mathrm{N}=$ population(1490), $\mathrm{e}=$ margin error (0.05). A total of sample size was 315 mothers

SAMPLING: While a total calculated sample size was 315, subsequently apurposive sample of 150 women meets the required criteria and agreed to participate in the study. They dividedinto two groups 75 women with early cord clamping ( $\leq 1 \mathrm{~min}$ after delivery)and 75 for delayed umbilical cord clamping ( $\geq 3 \mathrm{~min}$ after delivery) during the period from September 2015 to September 2016. The participants were selected according to the following criteria

\section{Inclusions Criteria}

1. Women aged 18-35 years.

2. Gestational age 37- 42 weeks.

3. Multipara having second to fourth delivery, singleton birth.

4. Free from medical disorders associated with pregnancy.

5. Expected to give birth vaginally (cephalic vaginal birth).

6. No obstetric complication during the $1^{\text {st }}$ stage of labor.

7. Thebirth weight ranged from 2500 to $4000 \mathrm{gm}$. 


\section{Exclusions Criteria}

1. Women who have negative Rhesus factor status $\left(\mathrm{Rh}^{-}\right)$.

2. Women have been given preterm birth (less than 37 weeks gestation).

3. Women have been given a breech or any abnormal presentation.

4. Women who give birth by cesarean section (CS).

5. Women with evidence of intrauterine growth restriction (IUGR) or congenital malformation.

\section{Tools of Data Collection}

The tools of data collection were developed and used by the researchers after reviewing the related literature. Two tools were used for the collection of the necessary data.

Tool I: Structured Interviewing Questionnaire Sheet which compromises from 3 parts:

Part 1: Women's general characteristics data such asweight, age, educational level, occupational status, and residence.

Part 2: Women's obstetrical history as menstrual history (duration of menstruation, menstrual regularity, amount of menstrual blood flow, menstrual disorder) and history of PPH.

Part 3: Prenatal data: The following information was collected from maternal health care records from the time of admission to antenatal care, weight, blood group, hemoglobin (HB)value, gestational age and antenatal visit.

Tool II: Maternal and Fetal Outcome Sheet which compromise from 2 parts:

Part 1: Maternal outcomes sheet: duration of the $3^{\text {rd }}$ stage of labor, hemoglobin and hematocrit level (assess the need for blood transfusion, postpartum hemorrhage, etc.) and placental separation (spontaneous or manual removal of the placenta).

Part 2: Neonatal outcomes sheet: umbilical cord hemoglobin (immediately after birth \&24hrs after delivery hematocrit level), RBCs count, bilirubin level, and the need for admission to Neonate Intensive Care Unit (NICU), and need for restitution.

\section{TOOLS VALIDITY}

All tools were tested for content validity by a jury of five experts in the obstetrics and gynecological nursing, pediatric nursing professor and one from biostatistics field.

\section{Tools Reliability}

Reliability of tools was tested by using Cronbach'sAlphacoefficient test, which revealed that the tool II (Maternal \& Neonatal outcomes assessment sheet). Consisted of relatively homogenous items as indicated by high reliability $=0.85 \& 0.87$, respectively.

\section{Pilot Study}

The pilot study was conducted on $10.0 \%$ of the total sample to test the feasibility \& the applicability of the tool, find out the possible obstacles or problems that might face the researchers and interfere with data collection, detect any problems peculiar to the statements as sequence of questions, clarity and estimate the time needed for data collection. The samples of the women included in the pilot study were excluded from the main study sample 


\section{FELID OF WORK}

The data were compiled by the researcher during the period of 13 months from the $1^{\text {st }}$ of September 2015 up to the end of September 2016. The present study was carried out through the following phases:

\section{Interviewing or Assessment Phase}

- The mothers were selected at their $1^{\text {st }}$ stage of labor by fitting eligibility criteria. The researchers explained the aim and approach of the study to every woman and then informed oral consents were obtained from all the eligible ones to participate in the study.

- The researchers started to collect baseline data using the tool (I) through interviewing technique to fill the tools. Each woman was questioned individually and they assured that confidentiality by the researchers. The mean time needed for each woman was about 25-35 min to fill a questionnaire. The antenatal data as medication, parity, gravidity, weight, and gestational age were collected from maternal records.

\section{Planning Phase}

- Women were randomized to two homogeneous groups, early or late cord clamping groups. Each group was randomly assigned to cord clamping at less than one minute for early clamping group, while the timing of late cord clamping and cutting was (1 to $3 \mathrm{~min}$.) and maintain the baby level in a low level of the placenta, random assignment was done by computer-generated tables.

- Closed impervious sequentially numbered covers that contained the assigned intervention used to cover the distribution, if at the time of delivery the woman was still considered qualified for the experimental, acceptance took place, and a wrapper was drawn and opened accordingly in the delivery room after deciding to include those who have uneventful pregnancies according to the previously mentioned criteria.

- Labor and delivery were performed following the obstetrics' standard practice of care at the hospital. In line with hospital routine, oxytocin (10 IU, corresponding to $16.7 \mu \mathrm{g}$ ) was administered intravenously to the mother immediately after cord clamping. After delivery, the women and their babies were cared for the according to clinical routines and early breastfeeding was recommended and encouraged.

- The researchers assessed all women among both groups for the duration of the $3^{\text {rd }}$ stage of labor. All women among both groups received uterotonic agents after cord clamping.

- After completion of these procedures, The obstetrician held the infant in asterile towel or blanket approximately 10 to 15 inches below the mother's introitus at vaginal delivery, the assistant nurse who attended the delivery room and previously informed about the nature of research used a stopwatch to check the time at which clamping was effectively accomplished. Care was taken that no tension or traction was placed on the cord.

\section{Implementation Phase}

- Physician was responsible for performing neonatal examinations, maternity \& newborn and pediatric nursing researchers were responsible for the data collection;blood samples collectedfrom women and their newborn and send to laboratory analyses. They were blinded to the infant's allocation group.

\section{Maternal Implementation}

1. The maternal outcome: assess the maternal outcomes through the length of the $3^{\text {rd }}$ stage of labor, mean blood loss, manual removal of the placenta, blood transfusion and use of therapeutic uterotonic. 
A Quasi-Experimental Study to Assess Consequences of Early Versus Delay Umbilical Cord Clamping on Maternal and Neonatal Outcomes in Beni-Suef city

2. For the measurement of maternal blood loss, all vaginal blood was collected immediately after the infant's delivery by placing a pan and pad under the woman's buttocks until she was transferred to the postpartum ward. The collected blood was poured in a graded jar, and blood volume was determined.

3. After delivery and getting birth, the estimated maternal postpartum blood loss was recorded by the researchers within two hrs after childbirth by weighing pads, sheets, and other textiles, and by measuring the volume of blood collected in a pan. The time between the fetal and placental delivery was noted.

\section{Neonatal Implementation}

1. The infant was warmly wrapped \& held below the level of the mother's abdomen to prevent heat loss while waiting cord clamping.

2. Before discharge from the labor unit to the postnatal ward, the researchers measured the time from complete delivery of the baby to the first clamp on the umbilical cord with a stopwatch.

3. Venous and arterial cord blood samples for assessment of hemoglobin from the double clamped segment of the umbilical cord in the both group with keep infant in a low level of the placental level.

4. Admission to the NICU within $24 \mathrm{hrs}$ after birth was followed for assessing neonatal outcomes.

\section{Evaluation Phase}

Measuring maternal and newborn outcomes:

- Assessment of postpartum hemorrhage was determined if blood loss exceeds $500 \mathrm{ml}$, furthermore, women were assessed for the need for blood transfusion and placental separation is a spontaneous or manual removal of it.

- Assess neonates' weight, treatment with phototherapy, admission to the NICU, neonatal HB level, distress jaundice requiring phototherapy and the need for resuscitation.

- In plain tubes, $4 \mathrm{ml}$ of maternal venous blood was collected for HB \& hematocrit estimation. Similarly, $4 \mathrm{ml}$ of the infants' venous blood extracted, twice, from the newborn: (1) umbilical veins blood sample immediately after clamping the umbilical cord; (2) antecubital vein blood sample after 24 hours in 2 tubes sealed at one end with modeling clay, to measure hematocrit, hemoglobin level, RBCs count and Bilirubin level by the cyanmethemoglobin method. ${ }^{[9]}$ The sample was sent immediately to the laboratory and all laboratory results were recorded and compared with normal levels to assess maternal and neonatal blood analysis, fetal anemia and outcomes used tool II (part 2) by the researchers.

\section{Administrative and Ethical Consideration}

The study was conducted after getting permission from the director of the hospital and head of the department of obstetrics \& gynecology of the general hospital in Beni-Suef city. Moreover, the aim of the study was explained to the women who participated in the research and oral consent was taken from all women who were agreeing to participate after reassuring them about the confidentiality \& privacy of all information and that information will be used only for the purposeful research. The researchers interviewed women at labor departments in Beni-Suef general hospital.

\section{Statistical Data Analysis}

- The data were computerized and analyzed using the statistical package for social science (SPSS) version 22.0. 
A Quasi-Experimental Study to Assess Consequences of Early Versus Delay Umbilical Cord Clamping on Maternal and Neonatal Outcomes in Beni-Suef city

- Data were presented using descriptive statistics in the form of a number, percentage, mean \& standard deviation (Mean $\pm \mathrm{SD}$ ).

- Quantitative continuous data were

1. Student t-test was used in case of comparisons between two groups.

2. Paired t-test was used for pre-post comparisons of the same sample.

3. Pearson correlation analysis was used for assessment of the inter-relationships among quantitative variables.

4. Columand Bar chart diagrams were used to express the graphical presentation of the data.

- Statistical significance was considered at $\mathrm{P}$-value $<0.05$.

\section{RESULTS}

The socio-demographic characteristics of mothers in the study sample are described in table 1. It illustrates that more than half of mothers in both groups of the study sample age between 20 to 35 years, around half and most of themwere secondary education and housewives. The findings of the present study revealed that both groups were comparable with no significant differences in respect to baseline characteristics as maternal age, occupation, education, and residence.

Table1. Socio-demographic characteristics of mothers in the study sample(n=150)

\begin{tabular}{|c|c|c|c|c|c|}
\hline \multirow[t]{2}{*}{ Women's characteristics } & \multicolumn{2}{|c|}{$\begin{array}{c}\text { Group1 }(\mathrm{N}=75) \\
\text { Early clamping }(<1 \mathrm{~min})\end{array}$} & \multicolumn{2}{|c|}{$\begin{array}{c}\text { Group2 }(\mathrm{No}=75) \\
\text { Late clamping }(1-3 \mathrm{mins})\end{array}$} & \multirow[t]{2}{*}{ P. value } \\
\hline & No & $\%$ & No & $\%$ & \\
\hline \multicolumn{6}{|l|}{ Women's age } \\
\hline$<20$ & 9 & 12.0 & 15 & 20.0 & \multirow{3}{*}{0.446} \\
\hline $20-35$ & 48 & 64.0 & 40 & 53.3 & \\
\hline$>35$ & 18 & 24.0 & 20 & 26.7 & \\
\hline Mean \pm SD & \multicolumn{2}{|c|}{$29.55+7.1$} & \multicolumn{2}{|c|}{$29.44+6.4$} & 0.818 \\
\hline Education & & & & & \multirow{5}{*}{0.622} \\
\hline Illiterate & 9 & 12.0 & 12 & 16.0 & \\
\hline Primary & 12 & 16.0 & 10 & 13.3 & \\
\hline Secondary & 32 & 42.7 & 35 & 46.7 & \\
\hline University & 22 & 29.3 & 18 & 24.0 & \\
\hline \multicolumn{6}{|l|}{ Residence } \\
\hline Urban & 33 & 44.0 & 47 & 62.7 & \multirow{2}{*}{0.472} \\
\hline Rural & 37 & 56.0 & 28 & 37.3 & \\
\hline \multicolumn{6}{|l|}{ Occupation } \\
\hline Housewife & 50 & 66.7 & 60 & 80.0 & \multirow{2}{*}{0.337} \\
\hline Employer & 25 & 33.3 & 15 & 20.0 & \\
\hline
\end{tabular}

Table (2) presented that no significant difference regarding regularity of menstruation, and history of menstrual disorders, however, a significant difference was observed regarding the previous history of PPH. Furthermore, both groups were comparable for gestational age, $1^{\text {st }}$ antenatal visit weight and amount of menstrual blood flow 
A Quasi-Experimental Study to Assess Consequences of Early Versus Delay Umbilical Cord Clamping on Maternal and Neonatal Outcomes in Beni-Suef city

Table2. Obstetrical history of the study sample. $(n=150)$

\begin{tabular}{|c|c|c|c|c|c|}
\hline \multirow[t]{2}{*}{ Obstetrical history } & \multicolumn{2}{|c|}{\begin{tabular}{|c} 
Group1 $(\mathrm{N}=75)$ \\
Early clamping $(<1 \mathrm{~min})$
\end{tabular}} & \multicolumn{2}{|c|}{$\begin{array}{l}\text { Group2 }(\mathrm{No}=75) \\
\text { Late clamping(1-3mins) }\end{array}$} & \multirow[t]{2}{*}{ P. value } \\
\hline & No & $\%$ & No & $\%$ & \\
\hline $\begin{array}{l}\text { Duration of menstruation } \\
\text { Mean } \pm \text { SD }\end{array}$ & \multicolumn{2}{|c|}{$2.4+0.45$} & \multicolumn{2}{|c|}{$2.1+0.41$} & 0.341 \\
\hline Menstrual regularity & & & & & \\
\hline $\begin{array}{l}\text { Regular } \\
\text { Irregular }\end{array}$ & $\begin{array}{l}50 \\
25 \\
\end{array}$ & $\begin{array}{l}66.7 \\
33.3 \\
\end{array}$ & $\begin{array}{l}45 \\
30 \\
\end{array}$ & $\begin{array}{l}60.0 \\
40.0\end{array}$ & 0.311 \\
\hline \multicolumn{5}{|l|}{ Menstrual disorder } & \multirow[b]{2}{*}{0.509} \\
\hline $\begin{array}{l}\text { No } \\
\text { Yes }\end{array}$ & $\begin{array}{l}55 \\
20\end{array}$ & $\begin{array}{l}73.3 \\
26.7\end{array}$ & $\begin{array}{l}60 \\
15\end{array}$ & $\begin{array}{l}80.0 \\
20.0\end{array}$ & \\
\hline \multicolumn{5}{|l|}{ Gestational age } & \multirow{11}{*}{0.545} \\
\hline 37 weeks & 0 & 0.0 & 0 & 0.0 & \\
\hline 38-40 weeks & 33 & 44.0 & 40 & 53.3 & \\
\hline $40-42$ weeks & 47 & 56.0 & 35 & 46.7 & \\
\hline \multicolumn{5}{|l|}{$\mathbf{1}^{\text {st }}$ Antenatal visit Weight } & \\
\hline$<60 \mathrm{~kg}$ & 1 & 1.3 & 3 & 4.0 & \\
\hline $61-70 \mathrm{~kg}$ & 12 & 16.0 & 15 & 20.0 & \\
\hline $71-80 \mathrm{~kg}$ & 22 & 29.4 & 20 & 26.7 & \\
\hline $81-90 \mathrm{~kg}$ & 19 & 25.3 & 17 & 22.6 & \\
\hline $91-100 \mathrm{~kg}$ & 21 & 28.0 & 20 & 26.7 & \\
\hline Mean \pm SD & \multicolumn{2}{|c|}{$38.7+5.2$} & \multicolumn{2}{|c|}{$41+5.3$} & \\
\hline $\begin{array}{l}\text { Amount of menstrual blood flow } \\
\text { Mean }+ \text { SD }\end{array}$ & \multicolumn{2}{|c|}{$8.33+2.4$} & \multicolumn{2}{|c|}{$9.32+2.7$} & 0.333 \\
\hline - Scanty (changed less than 4 pads during menstruation) & 32 & 42.7 & 30 & 40.0 & \\
\hline - Moderate (4-9 pads changed) & 41 & 54.7 & 40 & 53.3 & 0.532 \\
\hline - Excessive (more than 9 pads changed) & 2 & 2.6 & 5 & 6.7 & \\
\hline \multirow{3}{*}{$\begin{array}{l}\text { Past history of PPH } \\
\text { - No } \\
\text { - Yes }\end{array}$} & & & & & \\
\hline & 70 & 93.3 & 72 & 96.0 & $0.043^{*}$ \\
\hline & 5 & 6.7 & 3 & 4.0 & \\
\hline
\end{tabular}

Figure (1) displays the changes in hemoglobin level throughout the period of pre and post labor between early or late cord clamping groups of maternal hemoglobin level. It demonstrates increase the hemoglobin level in pre of both groups and it demonstrates slightly decrease in the post-partum maternal hemoglobin level post-labor of early and delayed cord clamping groups. 
A Quasi-Experimental Study to Assess Consequences of Early Versus Delay Umbilical Cord Clamping on Maternal and Neonatal Outcomes in Beni-Suef city

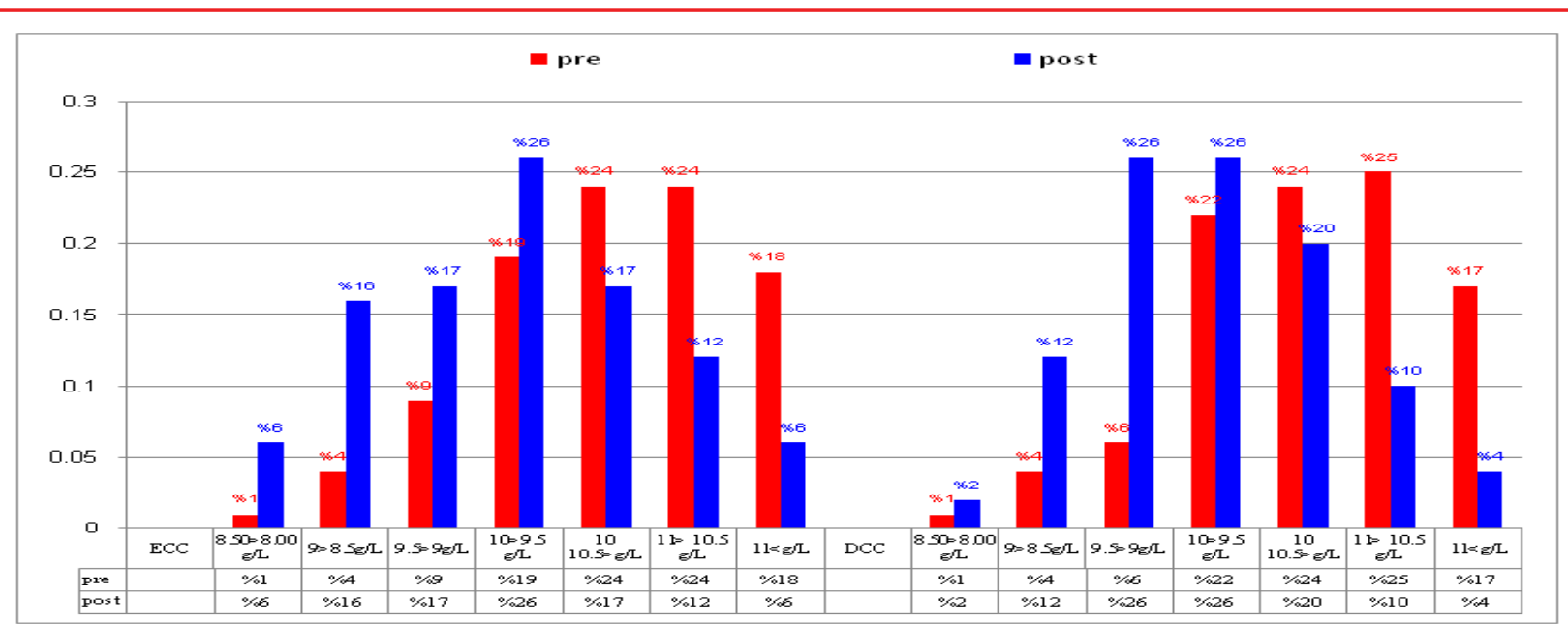

Fig1. Changes of maternal hemoglobin level $(\mathrm{g} / \mathrm{L})$ throughout the follow-up pre and post-delivery

Table (3) shows that no significant difference regarding maternal outcomes among both groups in respect to estimated postpartum blood loss, hemoglobin and hematocrit level and need for blood transfusion and $8 \%$ of them required manual removal of the placenta. The mean estimated postpartum blood loss, maternal hemoglobin and hematocrit levelwithin 24 hours of labor among early and late cord clamping $(516 \pm 65,562$ $\pm 112 \& 14.02 \pm 1.22,13.44 \pm 1.88 \& 40.30 \pm 4.38,35.08 \pm 5.66$ respectively) and postpartum blood loss was within the normal average of blood loss for vaginal delivery among early and late cord clamping. However, a significant difference was observed regarding the length of the third stage of labor, the mean duration of the third stage of labor took a shorter time for the early cord clamping group compared to late group (22.18 $\pm 3.4 \& 33.6 \pm 4.2$ minutes respectively). Additionally, the majority of the study sample didn't need for blood transfusion and all of the women received uterotonic after cord clamping.

Table3. Maternal characteristics' outcomes. $(n=150)$

\begin{tabular}{|c|c|c|c|c|c|}
\hline \multirow{3}{*}{ Maternal outcomes } & \multicolumn{2}{|c|}{ Group1 $(\mathrm{N}=75)$} & \multicolumn{2}{|c|}{ Group2 ( $\mathrm{No}=75)$} & \multirow{3}{*}{ P. value } \\
\hline & \multicolumn{2}{|c|}{$\begin{array}{l}\text { Early clamping }(<1 \\
\text { min })\end{array}$} & \multicolumn{2}{|c|}{\begin{tabular}{|lr} 
Late & clamping \\
$(1-3$ mins $)$ & \\
\end{tabular}} & \\
\hline & No & $\%$ & No & $\%$ & \\
\hline $\begin{array}{l}\text { Estimated Maternal a postpartum blood loss } \\
(\text { Mean } \pm \text { SD) }\end{array}$ & \multicolumn{2}{|c|}{$516 \pm 65$} & \multicolumn{2}{|c|}{$562 \pm 112$} & 0.476 \\
\hline No (blood loss $<500$ ) & 65 & 86.7 & 69 & 92.0 & \\
\hline Moderate (blood loss $500<1000$ ) & 10 & 13.3 & 6 & 8.0 & 0.458 \\
\hline Sever (blood loss $>1000$ ) & 0 & 0.0 & 0 & 0.0 & \\
\hline Maternal hemoglobin level (Mean \pm SD) & \multicolumn{2}{|c|}{$14.02 \pm 1.22$} & \multicolumn{2}{|c|}{$13.44 \pm 1.88$} & 0.382 \\
\hline Maternal hematocrit level $($ Mean \pm SD) & \multicolumn{2}{|c|}{$40.30 \pm 4.38$} & \multicolumn{2}{|c|}{$35.08 \pm 5.66$} & 0.821 \\
\hline Placental Separation & & & & & \\
\hline Spontaneous & 65 & 86.7 & 73 & 97.3 & 0212 \\
\hline Manual Removal & 10 & 13.3 & 2 & 2.7 & 0.212 \\
\hline Need for blood transfusion & & & & & \\
\hline No & 70 & 93.3 & 73 & 97.3 & 0.122 \\
\hline Yes & 5 & 6.7 & 2 & 2.7 & \\
\hline
\end{tabular}

American Research Journal of Nursing 
A Quasi-Experimental Study to Assess Consequences of Early Versus Delay Umbilical Cord Clamping on Maternal and Neonatal Outcomes in Beni-Suef city

\begin{tabular}{|l|c|c|c|c|c|}
\hline \hline Women received uterotonic after cord clamping & \multicolumn{2}{|c|}{$|c| c \mid$} & \\
No & 0 & 0.0 & 0 & 0.0 & \\
Yes & 75 & 100.0 & 75 & 100.0 & - \\
\hline Length of 3rd stage of labor (min) (Mean \pm SD) & \multicolumn{2}{|c|}{$22.18+3.4$} & \multicolumn{2}{|c|}{$33.6+4.2$} & \\
\hline Less than 20 min & 50 & 66.7 & 12 & 16.0 & \multirow{2}{*}{$0.001^{* *}$} \\
\cline { 2 - 5 } $20-30$ min & 25 & 33.3 & 43 & 57.3 & \\
\cline { 2 - 5 } More than 30 min & 0 & 0.0 & 20 & 26.7 & \\
\hline
\end{tabular}

As regards the neonatal outcomes, Table (4) revealed that, the neonatal mean of body weight was (4.1 \pm $0.7 \& 5.7 \pm 0.5$ ) and neonatal hematologic parameters were comparable and slightly raised in hematocrit and hemoglobin level at birth especially among late cord clamping group compared to early group with no significant differences however a significant difference was observed regarding these levels after 24 hours, furthermore no significant difference was detected regarding other neonatal variables as total Bilirubin count, polycythemia, anemia and need for admission to NICU. The incidence of newborns with a hematocrit level of $<45 \%$ and polycythemia or a hematocrit level of $>65 \%$ at birth and after 24 hours among the early and late group were lower in ECC but higher among the late cord clamping group compared to early cord clamping, but with no statistically significant differences.

Table4. Distribution of neonates according to their hematological parameters and neonatal outcomes

\begin{tabular}{|c|c|c|c|c|c|}
\hline \multirow[t]{2}{*}{ Neonatal Outcomes } & \multicolumn{2}{|c|}{$\begin{array}{l}\text { Group1 }(\mathrm{N}=75) \\
\text { Early clamping }(<1 \mathrm{~min})\end{array}$} & \multicolumn{2}{|c|}{$\begin{array}{l}\text { Group2 }(\mathrm{No}=75) \\
\text { Late clamping (1-3mins) }\end{array}$} & \multirow[t]{2}{*}{ P. value } \\
\hline & No & $\%$ & No & $\%$ & \\
\hline Baby weight(Mean \pm SD) & \multicolumn{2}{|c|}{$4.1 \pm 0.7$} & \multicolumn{2}{|c|}{$5.7 \pm 0.5$} & 0.268 \\
\hline $\begin{array}{l}\text { Neonatal Hematocrit level } \\
(\text { Mean } \pm \text { SD) At birth } \\
\text { (Mean } \pm \text { SD) After } 24 \text { hours }\end{array}$ & \multicolumn{2}{|c|}{$\begin{array}{l}65.4 \pm 6.6 \\
68.6 \pm 7.5\end{array}$} & \multicolumn{2}{|c|}{$\begin{array}{c}61.0 \pm 7.4 \\
63.8 \pm 8.2\end{array}$} & $\begin{array}{l}0.082 \\
0.062\end{array}$ \\
\hline $\begin{array}{l}\text { Neonatal hemoglobin level } \\
\text { (Mean } \pm \text { SD) At birth } \\
\text { (Mean } \pm \text { SD) After } 24 \text { hours }\end{array}$ & \multicolumn{2}{|c|}{$\begin{array}{c}19.4 \pm 2.4 \\
18.8 \pm 1.88\end{array}$} & \multicolumn{2}{|c|}{$\begin{array}{c}16.4 \pm 2.5 \\
19.7 \pm 2.3 \\
\end{array}$} & $\begin{array}{l}0.274 \\
0.042 \\
\end{array}$ \\
\hline $\begin{array}{l}\text { Neonatal RBCs counts } \\
(\text { Mean } \pm \text { SD) At birth } \\
(\text { Mean } \pm \text { SD) After } 24 \text { hours }\end{array}$ & \multicolumn{2}{|c|}{$\begin{array}{l}6.6 \pm 0.60 \\
7.3 \pm 0.71\end{array}$} & \multicolumn{2}{|c|}{$\begin{array}{c}7.3 \pm 1.2 \\
8.42 \pm 1.8\end{array}$} & $\begin{array}{c}0.044 \\
0.45\end{array}$ \\
\hline $\begin{array}{l}\text { Total Billirubin count } \\
\text { (Mean } \pm \text { SD) At birth } \\
(\text { Mean } \pm \text { SD) After } 24 \text { hours }\end{array}$ & \multicolumn{2}{|c|}{$\begin{array}{l}4.11 \pm 2.1 \\
4.8 \pm 2.8\end{array}$} & \multicolumn{2}{|c|}{$\begin{array}{c}4.84 \pm 3.2 \\
6.4 \pm 4.1\end{array}$} & $\begin{array}{l}0.06 \\
0.15\end{array}$ \\
\hline $\begin{array}{l}\text { Polycythemia } \\
\text { HCT }>65 \% \text { At birth } \\
\text { HCT }>65 \% \text { After } 24 \text { hours }\end{array}$ & $\begin{array}{l}1 \\
1 \\
\end{array}$ & $\begin{array}{l}1.33 \\
1.33\end{array}$ & $\begin{array}{l}4 \\
8\end{array}$ & $\begin{array}{c}5.33 \\
10.67 \\
\end{array}$ & 0.976 \\
\hline $\begin{array}{l}\text { Anemia } \\
\text { HCT }<45 \% \text { At birth } \\
\text { HCT }<45 \% \text { After } 24 \text { hours }\end{array}$ & $\begin{array}{l}2 \\
2 \\
\end{array}$ & $\begin{array}{l}2.67 \\
2.67 \\
\end{array}$ & $\begin{array}{l}1 \\
0\end{array}$ & $\begin{array}{c}1.33 \\
0.0 \\
\end{array}$ & 0.083 \\
\hline $\begin{array}{l}\text { Need for resuscitation } \\
\text { No } \\
\text { Yes }\end{array}$ & $\begin{array}{c}75 \\
0\end{array}$ & $\begin{array}{c}100.0 \\
0.0\end{array}$ & $\begin{array}{c}73 \\
2\end{array}$ & $\begin{array}{c}97.3 \\
2.7\end{array}$ & -- \\
\hline
\end{tabular}

American Research Journal of Nursing 
A Quasi-Experimental Study to Assess Consequences of Early Versus Delay Umbilical Cord Clamping on Maternal and Neonatal Outcomes in Beni-Suef city

Figure (2): illustrated the hemoglobin level of the neonate among early \&late cord clamping. The hemoglobin level of neonates in the ECC study sample was increased than ECC study group. It demonstrates that in the DCC study sample hemoglobin level had ranged between 15 to $17 \mathrm{~g} / \mathrm{L}$ (36.0\%) and about 32.0\% had hemoglobin level ranged from 19 to $21 \mathrm{~g} / \mathrm{L}$.

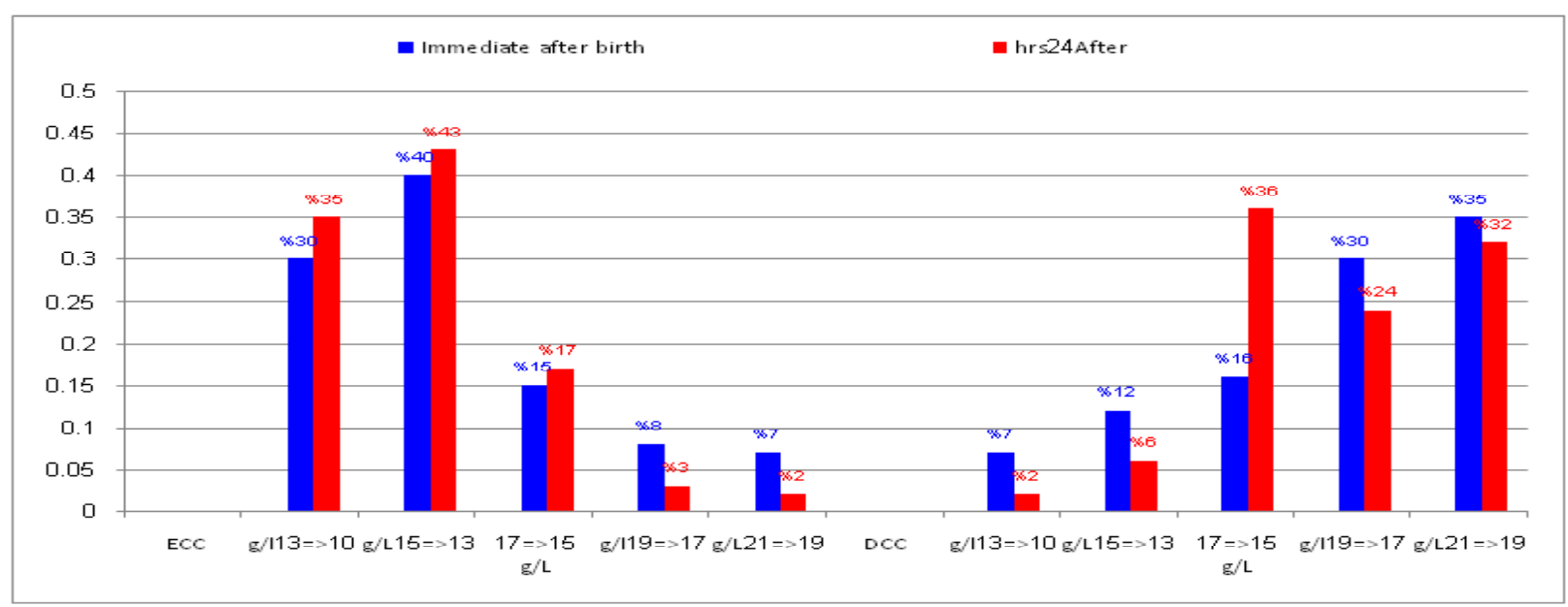

Fig2. Distribution of hemoglobin level of neonate after birth and after 24hrs of delivery between ECCand $D C C(N o=150)$

The comparison between delayed and ECC groups regarding the neonatal need for admission to NICU is displayed in Figure (3). The figure revealed that the majority of study sample did not need for admission to NICU.

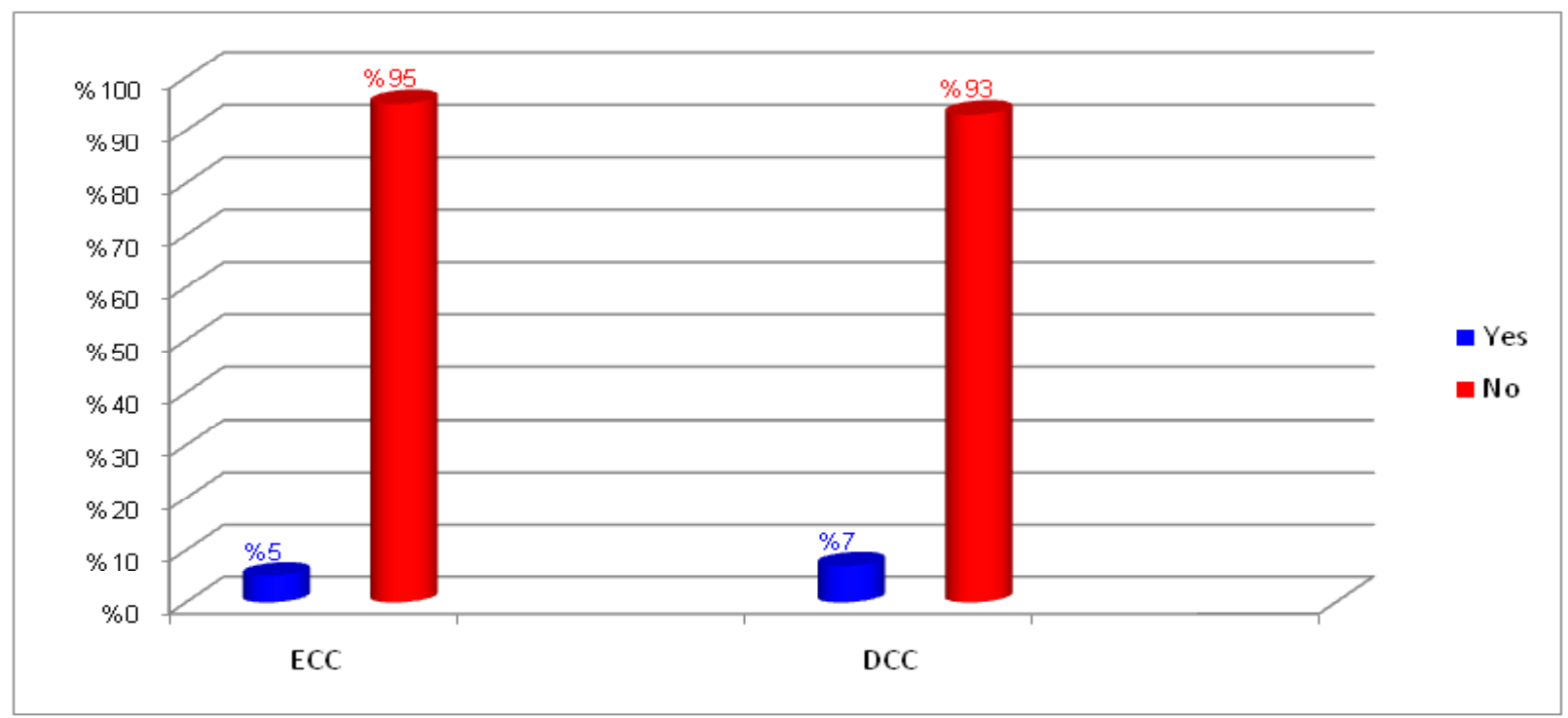

Fig3. Comparison Between Delayed and ECCGroups Regarding Neonatal Need for Admission to NICU.

\section{DiscusSION}

In the developed world without scientific assessment of its potential effect on a newborn's health, obstetricians and midwives choose when to clamp and cut the umbilical cord. ${ }^{[26]}$ Nursing personnel plays an important role in the labor area especially in the $3^{\text {rd }}$ stage of labor, so nurses should have the basic necessary knowledge and technical skills to offer the care safely, be trained accurately in practical and technical procedures to be able 
A Quasi-Experimental Study to Assess Consequences of Early Versus Delay Umbilical Cord Clamping on Maternal and Neonatal Outcomes in Beni-Suef city

to use this knowledge effectively ${ }^{[27]}$ Early cord clampinghas converted the routine practice as a part of active management of the $3^{\text {rd }}$ stage of labor. Furthermore, ECC as a part of the active management of the $3^{\text {rd }}$ stage of labor is supposed to significantly reduce the hazard of PPH. Since many active management protocols include ECC, leading some to suggest that DCC may increasethe hazard for PPH. On the contrary, recent protocol proposed by WHOto treat the $3^{\text {rd }}$ stage of laborswitched the ECCby DCCto induce numerous neonatal benefits. However, delayed versus immediate cord clamping is not generallyrecognized as part of the management of the $3^{\text {rd }}$ stage of labor. ${ }^{[26]}$ In addition, fear of polycythemia, respiratory distress, and hyperbilirubinemia are concerns that have caught up the practice of DCC as routine care. ${ }^{[28]}$

The umbilical cord clamping time may have a vital impact on a population's health, as revealed by the results of this study and prior data. Even small effects on each individual may have a great impact when multiplied in a large population. Many clinical trials examined the effects of late umbilical cord clamping on both mother and their infant. Therefore many variations were reported in the timing of umbilical cord clamping, this can be immediately after birth within a set time after birth either within 30 seconds to minute, or any time before umbilical cord pulsation ceases. ${ }^{[29]}$ The aim of the present study was to evaluate the consequences of early versus delay umbilical cord clamping on both maternal \&neonatal outcomes.

As regarding socio-demographic characteristics and maternal outcomes, the present study revealed that there was no statistically significant difference between both early and delayed group. Both groups were comparable with no significant difference regarding menstrual and obstetric history parameters however a significant difference was observed regarding the length of the $3^{\text {rd }}$ stage of labor, the mean duration of the $3^{\text {rd }}$ stage of labor took a shorter time for the early cord clamping group compared to the late group. This finding was in the same line withAhmad et al (2012)who found thatno statistically significant difference regarding sociodemographic data between both groups was comparable of study subjects except menstrual and obstetric history parameters, however, the only significant difference in her study about effect of early versus late umbilical cord clamping of term infants on maternal and neonatal outcomes at Assiut University. ${ }^{[30]}$ This finding was supported by Inch (1985) who underlined that early cord clamping has been related to a reduction in the length of the $3^{\text {rd }}$ stage of labor. ${ }^{[31]}$ As of the aims of active management is to decrease the length of the $3^{\text {rd }}$ stage because of the extended time of placenta remains undelivered. On the contrary, Abalos (2009) stated that, no differences between both groups in respect to the duration of the $3^{\text {rd }}$ stage of labor, in his study about the effect of timing of umbilical cord clamping of term infants on maternal \&neonatal outcomes. ${ }^{[32]}$

The present study results denoted that, there was no significant difference between DCC \& ECC groups in relation to estimated a maternal postpartum blood loss, maternal hemoglobin, hematocrit levels and needs for blood transfusion $(421 \pm 67,435 \pm 125 \& 14.02 \pm 1.22,13.44 \pm 1.88 \& 40.30 \pm 4.38,35.08 \pm 5.66)$, respectively. Whereas, more than three-quarters of both groups DCC a ECC lost normal amount postpartum blood loss(blood loss was $<500 \mathrm{ml}$ ). Severe PPH (blood loss $>1000 \mathrm{ml}$ ) was not detected in the both groups. The results of this study supported by Backes et al (2015) who stated that, no benefit of ECC for the prevention of PPH in his study about "the effect of early versus delayed umbilical cord clamping in infants with congenital heart disease. ${ }^{[33]}$ Moreover, the study results supported by Ceriani et al (2006)who also recorded cases which suffered from post-partum hemorrhage. Postpartum hemorrhage (blood loss $>500 \mathrm{ml}$ ) wasdecreased among late cord clamping group compared to early group (26.8\% in the ECC group, $22.2 \%$ in the 1-minute cord clamping group, and $25.4 \%$ in the 3-minute cord clamping group). ${ }^{[34]}$ Severe postpartum hemorrhage (blood loss $>1000 \mathrm{ml}$ ) was $3.6 \%$, $5.6 \%, \& 3.2 \%$ in each group, respectively, in his study about the effect of timing of cord clamping on neonatal venous hematocrit values \& clinical outcome at term. ${ }^{[34]}$ In this Ahmad et al (2012) respectmentioned that, no significant difference was detected in early \& late cord clamping groups in maternal hemoglobin \& hematocrit 
A Quasi-Experimental Study to Assess Consequences of Early Versus Delay Umbilical Cord Clamping on Maternal and Neonatal Outcomes in Beni-Suef city

levels (12.01 $\pm 0.97 \& 11.7 \pm 1.35$ and $33.59 \pm 3.57 \& 33.52 \pm 4.44$ respectively) in her study about effect of early VS late umbilical cord clamping of term infants on maternal and neonatal outcomes at Assiut University. ${ }^{[30]}$ This finding unsupported by Nesheli et al (2014) who stated that, DCCmay increase rates of hyperbilirubinaemia, polycythaemia, and transient tachypnoea in the newborn or maternal haemorrhage in his study about effect of late VS early clamping of the umbilical cord (on hemoglobin level) in full-term neonates at Mazandaran University of Medical Sciences, Sari, Iran. ${ }^{[2]}$ Regarding the need for blood transfusion, the result of the present study showed that the majority among early group compared to all women among the late group not need blood transfusion with no significant difference. This is agreed with Abalos (2009) who reported that there were no statistically significant differences in need for blood transfusion between the early \&late cord clamping groups in his study aboutthe effect of timing of umbilical cord clamping of term infants on maternal \&neonatal outcomes at Geneva. ${ }^{[32]}$

As regarding placental separation (spontaneous VS manual removal) and uterotonic agents administered following birth and previous to cord clamping have been revealed to rise the rate of placental transfusion and are thus likely to increase the effect of delayed clamping and the present study revealed that, there was no statistically significant difference between both early and delayed group in placental separation(spontaneous VS manual removal ) andall women of both groups received uterotonic. Mc Donald et al (2013) found that all women of both groups received uterotonic after cord clamping and showed no significant differences in the need for therapeutic administration of uterotonic between the early VS late cord clamping groups in his study about Effect of timing of umbilical cord clamping of term infants on maternal \&neonatal outcomes. ${ }^{[35]}$

Regarding distribution of neonates according to their hematological parameters \& neonatal outcomes about consequences of early versus delay umbilical cord clamping on maternal \& neonatal outcomes, the current study stated thatthere were slightly raised in hematocrit and hemoglobin level at birth especially among late cord clamping group compared to early group with no significant differences however a significant difference was observed regarding these levels after 24 hours. This findings agreed with Nesheli et al (2014) who found that, DCCpermitting placental transfusion post-delivery can provide the newborn with a $30 \%$ increase the blood volume and up to a $60 \%$ increase in red blood cells (RBCs) in his study about effect of late VS early clamping of the umbilical cord (on hemoglobin level) in full-term neonates at Mazandaran University of Medical Sciences, Sari, Iran. ${ }^{[22]}$ Moreover, Bolstridge et al (2016) added that DCCreduces the need for blood transfusions by reducing the incidence of iron deficiency anemia. ${ }^{[36]}$ Though enhancements in hemoglobin concentrations are more passing, newborns delivery ECC have decreased iron stores and are twice as likely to be iron deficient at three to six months of age in his study aboutA quality improvement initiative for delayed umbilical cord clamping in very-low-birth-weight infants at Department of Neonatology, Christiana Care Health System USA. In agreement with Ishtiaq \& Bano (2013) who found that the prevalence of neonatal anemia at six hrs was more when the cord was clamped early. In group (1), 8\% neonates were set up anemic with no incidence of polycythemia. In group 2 , the prevalence of anemia was $6 \%$. Only $4 \%$ of the newborns in group3 were originated to beanemic,while in group 4, no newborn was found to be anemic of compared ECCand DCCgroups in his study about effect of timing of cord clamping on neonatal venous hematocrit \& clinical outcome at term-hospital-based randomized control trial. Which the study sample was divided into 4 groups of 50 each wherein the umbilical cord was clamped at 15 seconds, 30 seconds, 1 minute and 2 minutes respectively. ${ }^{[37]}$

Polycythemia or a hematocrit level of $>65 \%$ at birth \& after 24 hours among early \& late group was lower in ECC but higher among the late cord clamping group compared to early cord clamping, this result supported by Ishtiaq \& Bano (2013) who stated that,in group 4 polycythemia occurred in $6 \%$ of cases and no found anemic 
newborn where as polycythemia presented in $8 \%$ of the newborns in prevalence polycythemia at 6 hours. While prevalence polycythemia at 24 hours was one neonate developed polycythemia. In group 4 , only 1 neonate was found to be anemic whereas 8\% were polycythemic of DCC group in his study about effect of timing of cord clamping on neonatal venous hematocrit and clinical outcome at term-hospital-based randomized control trial. ${ }^{\left[{ }^{37]}\right.}$ Which the study sample was divided into 4 groups of 50 each wherein the umbilical cord was clamped at 15 seconds, 30 seconds, 1 minute and 2 minutes respectively. Additionally, Nesheli et al (2014) stated that, DCCmay increase rates of hyperbilirubinaemia, polycythaemia, and transient tachypnoea in the newborn or maternal haemorrhage in his study about effect of late versus early clamping of the umbilical cord (on hemoglobin level) in full-term neonates at Mazandaran University of Medical Sciences, Sari, Iran. But with no statistically significant differences between ECC\&DCCin polycythemia or a hematocrit level. ${ }^{[22]}$ The results of current study was agreed with Ahmad et al (2012) who mentioned that, no significant difference was detected in early \& late cord clamping groups in polycythemia or ahematocrit level in her study about effect of early versus late umbilical cord clamping of term infants on maternal \& neonatal outcomes at Assiut University. ${ }^{[30]}$

\section{CONCLUSION}

In the bright of the central study results, it was concluded that, the DCC have clinical benefits on both maternal and neonatal outcome than ECC. So the hypothesis of the study is accepted. Moreover, the DCC of the cord for at 1-3 minutesappears not to increase the risk of postpartum hemorrhage. In addition, DCC can be helpful for the infant by increasing hematological values especially the status which may be of clinical value particularly for the newborn in developing nations where access to good nutrition is poor. Thus, this interference appears to be safe, effective and of acertain importance for developing countries in which anemia during infancy \& child hood is extremely predominant, it is likely to have a significant effect on all newborns, regardless of birth setting and could be applied without problems. Henceforth, as this study supports, the clamping of the umbilical cord may be late at least up to 2 minutes to get the optimum advantage and decrease of DCC risk

\section{RECOMMENDATIONS}

Based on the findings of the present study, it is recommended that

1. Delay cord clamping should be consistent practice and maintained by the ministry of health and hospital administration.

2. Increasing attentiveness of the routine DCC by obstetricians and midwives and reflect this practice as one of the total quality standers to achieve the mothers \& babies benefits under control of DCC time.

3. Future study should also be aimed at women's views \& newborn effect related to this intervention.

4. Future research should also be carried out on large numbers of parturient and their neonates and do not extend time of DCC to decrease risk of DCC such as (hyperbilirubinaemia, polycythaemia, and transient tachypnea)

5. Additional study may be useful in refining the timing of clamping by determining the minimum time required to provide maximum benefit associated with placental transfusion and neonatal impact

\section{LIMITATION OF STUDY}

To collect data on time of delivery it was considering a challenge to fill all variables of the questionnaire to assess maternal and neonate outcomes.

\section{CONFLICTS OF INTEREST DISCLOSURE}

The authors declare that there is no conflict of interest. 
A Quasi-Experimental Study to Assess Consequences of Early Versus Delay Umbilical Cord Clamping on Maternal and Neonatal Outcomes in Beni-Suef city

\section{REFERENCES}

1. Raju T. And Singal N. Optimal Timing For Clamping the Umbilical Cord after Birth. ClinPerinatol. 2012; December; 39(4).

2. Ceriani Cernadas, JM. The WHO Reproductive Health Library. Geneva: World Health Organization; 2006. Early versus delayed umbilical cord clamping in preterm infants: RHL commentary (last revised 7 March 2006). Cited from http://apps.who.int/rhl/pregnancy_childbirth/ childbirth/3rd_stage/jccom/en/.

3. The WHO Reproductive Health Library: Optimal timing of cord clamping for the prevention of iron deficiency anaemia in infants The World Health Organization (last update 2 March 2012). http://www. who.int/elena/titles/cord_clamping/en/.

4. Galel SA., Fontaine MJ. Hazards of neonatal blood transfusion. Neo Reviews. 2006;7:e69-75.

5. Mc Donald S.Physiology and management of the third stage of labour. 2003; In: Fraser D. \& Cooper M. Myles text book for mid-wives. $14^{\text {th }}$ Edition. Edinburgh: Churchill Livingstone, Carroll P, Christensen R. New and underutilized uses of umbilical cord blood in neonatal care. Maternal Health, Neonatology and Perinatology (2015) 1:16. DOI 10.1186/s40748-015-0017-2.

6. Niermeyer S. A physiologic approach to cord clamping: Clinical issues. Maternal Health, Neonatology, and Perinatology (2015) 1:21.

7. BolstridgeJ., Bell T., Dean B., Mackley A., Moore G., Cheryl Swift C. et al. A quality improvement initiative for delayed umbilical cord clamping in very low-birth weight infants. BMC Pediatrics (2016) 16:155.

8. Rabe H., Diaz-Rossello JL., Duley L., et al. Effect of timing of umbilical cord clamping and other strategies to influence placental transfusion at preterm birth on maternal and infant outcomes. Cochrane Database Syst Rev. 2012; 15(8):CD003248. doi:10.1002/14651858.CD003248.pub3.

9. WHO. Technical Consultation on Postpartum and Postnatal Care. Department of making pregnancy safer. WHO/MPS/10.03. Geneva, October 18-20, 2006.

10. FathimaN.,\&Ramana R.M.V. An evaluation of the practice of active management of third stage of labour in a teaching hospital. Int J Reprod Contracept Obstet Gynecol 2016; 5: 1705-8.

11. GülmezogluA.M., Lumbiganon P., Landoulsi S., Widmer M., Abdel-Aleem H., Festin, M., Carroli, G., Qureshi, Z., Souza, J.P., Bergel, E., et al. Active management of the third stage of labour with and without controlled cord traction: a randomized, controlled, no inferiority trial. Lancet, 2012 May 5; 379(9827): 1721-1727.

12. Westhoff, G., Cotter, A.M., \& Tolosa, J.E. Prophylactic oxytocin for the third stage of labour to prevent postpartum hemorrhage. Cochrane Database Syst Rev. 2013 Oct 30; (10): CD001808.

13. Boere I, Roest AA, Wallace E, et al. Umbilical blood flow patterns directly after birth before delayed cord clamping. Arch Dis Child Fetal Neonatal Ed. 2015;100:F121-5. doi:10.1136/archdischild-2014-307144.

14. BolstridgeJ, Bell T, Dean B, Mackley A, Moore G, Cheryl Swift C et al. A quality improvement initiative for delayed umbilical cord clamping in very low-birth weight infants. BMC Pediatrics (2016) 16:155 .

15. Rabe H, Diaz-Rossello JL, Duley L, et al. Effect of timing of umbilical cord clamping and other strategies to influence placental transfusion at preterm birth on maternal and infant outcomes. Cochrane Database Syst Rev. 2012;15(8):CD003248. doi:10.1002/14651858.CD003248.pub3. 
A Quasi-Experimental Study to Assess Consequences of Early Versus Delay Umbilical Cord Clamping on Maternal and Neonatal Outcomes in Beni-Suef city

16. McDonald SJ, Middleton P, Dowswell T, Morris PS. Effect of timing of umbilical cord clamping of term infants on maternal and neonatal outcomes. Cochrane Database Syst Rev. 2013;11(7):CD004074. doi:10.1002/ 14651858.CD004074.pub3.

17. Raju TNK. Timing of umbilical cord clamping after birth for optimizing placental transfusion. Curr Opin Pediatr. 2013; 25:180-7.

18. Bhatt S, Alison B, Wallace1 E, , Crossley K, Gill A. Kluckow M, et al. Delaying cord clamping until ventilation onset improves cardiovascular function at birth in preterm lambs J Physiol 591.8 (2013) pp 2113-2126.

19. Hassan H., Mohamady Sh., \&Abd El-Gawad N. Protocol for improving nursing performance towards placental examination at labor units. Clinical Nursing Studies, 2017; 5(2): 1-11. http://dx.doi.org/10.5430/cns. v5n2p1.

20. Sommers R, Stonestreet BS, Oh W, et al. Hemodynamic effects of delayed cord clamping in premature infants. Pediatrics. 2012; 129: e667-e672.

21. Elgzar W., Taha I., Ibrahim H., A.,, and Elkhateeb H., H., "Effects of Deferred Versus Early Umbilical Cord Clamping on Maternal and Neonatal Outcomes." American Journal of Nursing Research, vol.5, no. 4 (2017): 115-128. doi: 10.12691/ajnr-5-4-3.

22. Nesheli ,H., M., Esmailzadeh, S., Haghshenas, M., Bijani, A., Moghaddam T.,G., (2014):Effect of late vs early clamping of the umbilical cord (on hemoglobin level) in full-term neonates. SHORT COMMUNICATION. Vol. 64, No. 11, November 2014 Mazandaran University of Medical Sciences, Sari, Iran.

23. Sarıcı SU, Ozcan M, Altun D (2016) Neonatal Polycythemia: A Review. Clin Med Rev Case Rep 3:142Clin Med Rev Case Rep 2016, 3:142. ISSN: 2378-3656. Volume 3 | Issue 11Clin Med Rev Case Rep 2016, 3:142.

24. Beni-Suef General Hospital Census, (2014): obstetric department census.

25. Yamane T. Statistics an Introductory Analysis. 1967, 2nd Ed. New York Harper and Row CO.USA, 213.

26. Garofalo, M., \& Abenhaim, H.A. Early versus delayed cord clamping in term and preterm births: a review. J ObstetGynaecol Can. 2012 Jun; 34(6): 525-31.

27. Hassan H., and Nasr E. Improving nurses' knowledge and skills regarding tocolytics for inhibiting preterm labor. Clinical Nursing Studies, 2017; 5(1): 1-12. http://dx.doi.org/10.5430/cns.v5n1p1.

28. Mercer, J.S., Erickson-Owens, D.A., Collins, J., Barcelos, M.O., Parker, A.B., \& Padbury, J.F. Effects of delayed cord clamping on residual placental blood volume, hemoglobin and bilirubin levels in term infants: a randomized controlled trial. JPerinatol. 2017 Mar; 37(3): 260-264.

29. Van Rheenan 2007. Van Rheenen P, De Moor L, Eschbach S, De Grooth H, Brabin B. Delayed cord clamping and haemoglobin levels in infancy: a randomised controlled trial in term babies. Tropical Medicine \& International Health. 2007; 12(5):603-16. [PubMed: 17445128]

30. Ahmad E.,R.,, Alys.,A., and Zahran K., M. (2012): Effect of Early Versus Late Umbilical Cord Clamping of Term Infants on Maternal and Neonatal Outcomes. J Am Sci 2012;8(9):745-752]. (ISSN: 1545-1003). http:// www.americanscience.org. 102.

31. Inch S. Management of the third stage of labour: another cascade of intervention?. Midwifery 1985;1:114-22.

32. Abalos E. Effect of timing of umbilical cord clamping of term infants on maternal and neonatal outcomes: RHL commentary. The WHO Reproductive Health Library; Geneva: 2009; World Health Organization.

American Research Journal of Nursing

Page 16 
A Quasi-Experimental Study to Assess Consequences of Early Versus Delay Umbilical Cord Clamping on Maternal and Neonatal Outcomes in Beni-Suef city

33. Backes, C.H., Huang, H., Cua, C.L., Garg, V., Smith, C.V., Yin, H., Galantowicz, M., Bauer, J.A., \& Hoffman, T.M. Early versus delayed umbilical cord clamping in infants with congenital heart disease: a pilot, randomized, controlled trial. J Perinatol. 2015 Oct; 35(10): 826-831.

34. Ceriani C, Guillermo C, Liliana P (2006). The Effect of timing of cord clamping on neonatal venous hematocrit values and clinical outcome at term. Pediatrics; 117: e779-e786. Clin Med International Library.

35. McDonald SJ, Middleton P, Dowswell T, Morris PS. Effect of timing of umbilical cord clamping of term infants on maternal and neonatal outcomes. Cochrane Database of Systematic Reviews 2013, Issue 7. Art. No.: CD004074. DOI: 10.1002/14651858.CD004074.pub3. www.cochranelibrary.com.

36. Bolstridge J., Barbara T., Mackley, A., Moore, G., Swift,c., Viscount,D., David A. and Stephen A. Pearlman (2016): A quality improvement initiative for delayed umbilical cord clamping in very low-birth weight infants. BMC Pediatrics (2016) 16:155 DOI 10.1186/s12887-016-0692-9 Department of Neonatology, Christiana Care Health System, 4755 Ogletown Stanton Rd, Suite 217, MAP I, Newark, DE 19718, USA.

37. Ishtiaq, A., and Bano,I., (2013): Effect of timing of cord clamping on neonatal venous hematocrit and clinical outcome at term-hospital based randomized control trial. Journal of Medicine and Medical Sciences Vol. 8(1) pp. 001-006, March 2017 Available online http://www.interesjournals.org/JMMS DOI: http:/dx.doi. org/10.14303/jmms.2016.143.

Citation: Safaa Soliman Ahmed, Sahar Sedky Faheim, Hanan Elzeblawy Hassan, Mohamed Meabed " $A$ Quasi-Experimental Study to Assess Consequences of Early Versus Delay Umbilical Cord Clamping on Maternal and Neonatal Outcomes in Beni-Suef city". American Research Journal of Nursing. 2017; 3(1): 1-17.

Copyright (c) 2017 Safaa Soliman Ahmed, Sahar Sedky Faheim, Hanan Elzeblawy Hassan, Mohamed Meabed, This is an open access article distributed under the Creative Commons Attribution License, which permits unrestricted use, distribution, and reproduction in any medium, provided the original work is properly cited. 